\title{
OBVIOUS AND NOT OBVIOUS IN WITNESS IMMUNITY (THE EXPERIENCE OF THE COMPARATIVE LEGAL ANALYSIS)
}

\author{
Alexander A. Tarasov \\ Bashkir State University, Ufa, Russian Federation
}

\begin{abstract}
Introduction: witness immunity - that is, the right of certain categories of persons to give testimony about some of the known circumstances, is a penal institution, objectively associated with the whole complex of problems of the criminal justice system - its participants, the proof in criminal cases, the right to protection and qualified legal assistance, etc. The historical and comparative legal analysis of the legislative consolidation of witness immunity opens up new opportunities for the study of this whole complex of theoretical and practical problems. The aim is to determine the best ways to improve its legal definition and implementation practice based on the analysis of different legislative formulations on witness immunity. The main research methods are the methods of comparative law, historicism and system-structural analysis. Results: the trends in the development of the legal definition of witness immunity in the domestic legislation, the similarities and differences in the solution of similar issues in the legislation of the Federal Republic of Germany, the relationship of both with the socio-economic and political processes in both states are revealed. Conclusions: 1) witness immunity as a social and legal institution is a reflection of the global processes of development of society, the state and the national legal system;2) the comparative legal analysis of the legislative definition of witness immunity in different states allows us to identify the best ways to solve many criminal procedural and other legal problems.
\end{abstract}

Key words: witness immunity, criminal procedure, witness testimony, interrogation, witness, legal comparative studies, personal and family secrets, private life secrets, professional secrets.

Citation. Tarasov A.A. Obvious and not Obvious in Witness Immunity (The Experience of the Comparative Legal Analysis). Legal Concept = Pravovaya paradigma, 2021, vol. 20, no. 1, pp. 124-129. (in Russian). DOI: https://doi.org/10.15688/lc.jvolsu.2021.1.19

УДК 343.1

Дата поступления статьи: 08.01.2021

ББК 67.410 .2

Дата принятия статьи: 09.02.2021

\section{ОЧЕВИДНОЕ И НЕ ОЧЕВИДНОЕ В СВИДЕТЕЛЬСКОМ ИММУНИТЕТЕ (ОПЫТ СРАВНИТЕЛЬНО-ПРАВОВОГО АНАЛИЗА)}

\author{
Александр Алексеевич Тарасов \\ Башкирский государственный университет, г. Уфа, Российская Федерация
}

\begin{abstract}
Введение: свидетельский иммунитет - то есть право отдельных категорий лиц не давать свидетельских показаний о каких-то известных им обстоятельствах - это уголовно-процессуальный институт, объективно связанный с целым комплексом проблем системы уголовного судопроизводства - участниками его, доказыванием по уголовным делам, правом на защиту и квалифицированную юридическую помощь и т. д. Истори- ческий и сравнительно-правовой анализ законодательного закрепления свидетельского иммунитета открыکิ్ㅗ вает новые возможности для исследования всего этого комплекса теоретических и практических проблем. Цель - на основе анализа разных законодательных формулировок о свидетельском иммунитете определить оптимальные пути совершенствования его нормативно-правового определения и практики реализации. Осо новными методами исследования избраны метод сравнительного правоведения, метод историзма и метод с системно-структурного анализа. Результат: выявлены тенденции развития нормативно-правового определеЕ ния свидетельского иммунитета в отечественном законодательстве, сходства и различия с решением аналогич() ных вопросов в законодательстве Федеративной Республики Германии, связь того и другого с социально-
\end{abstract}


экономическими и политическими процессами в обоих государствах. Выводы: 1) свидетельский иммунитет как социально-правовой институт является отражением глобальных процессов развития общества, государства и национальной правовой системы; 2) сравнительно-правовой анализ законодательного определения свидетельского иммунитета в разных государствах позволяет выявить оптимальные пути решения многих уголовно-процессуальных и иных правовых проблем.

Ключевые слова: свидетельский иммунитет, уголовный процесс, свидетельские показания, допрос, свидетель, правовая компаративистика, личная и семейная тайна, тайна частной жизни, профессиональная тайна.

Цитирование. Тарасов А. А. Очевидное и не очевидное в свидетельском иммунитете (опыт сравнительно-правового анализа) // Legal Concept = Правовая парадигма. - 2021. - Т. 20, № 1. - C. 124-129. - DOI: https://doi.org/10.15688/lc.jvolsu.2021.1.19

\section{Свидетельский иммунитет как показатель уровня развития национальной системы уголовного процесса}

Свидетельский иммунитет - то есть право не давать свидетельских показаний в отношении конкретных лиц или об обстоятельствах, ставших данному человеку известными при осуществлении каких-то видов деятельности, - это один из уголовно-процессуальных иммунитетов, известных всем или почти всем современным национальным системам уголовного процесса. В праве человека отказаться давать показания, могущие навредить либо кому-то из его близких, либо другим лицам, доверившим потенциальному свидетелю личную или семейную или какуюто другую охраняемую нормами права тайну, сосредоточены одновременно многие социальные ценности, в защите которых общество и государство заинтересованы не менее, чем в раскрытии преступлений и в доказывании виновности в их совершении конкретных лиц. Тем менее понятно, что в нашей относительно недавней истории - в период действия последнего советского УПК РСФСР 1960 г. свидетельский иммунитет в связи с отношениями супружества или близкого родства не был закреплен вовсе. Это неизменно критически оценивалось в уголовно-процессуальной науке тех лет с апелляциями к общепринятым, а потому очевидным, нравственным категориям [4, с. 111].

В УПК РСФСР 1960 г., применявшимся вплоть до 1 июля 2002 г., положения о свидетельском иммунитете, обусловленном отношениями супружества и близкого родства, так и не были внесены. В едином закрытом перечне в качестве лиц, которые не могут быть допрошены в качестве свидетелей, в ст. 72 УПК РСФСР были названы адвокаты-защитники, адвокаты-представители и представители профсоюзных и общественных организаций, выполняющих аналогичные функции, а также лица, не способные в силу физических или психических недостатков давать свидетельские показания.

Полагаем, что и ограниченность норм о свидетельском иммунитете, и явная бессистемность их изложения в законе указывают на отсутствие концептуальной ориентации советского законодателя тех времен на охрану очевидно необходимого цивилизованному обществу права отказаться от дачи показаний в тех случаях, когда эти показания могут навредить значимым социальным интересам и ценностям.

\section{Свидетельский иммунитет в действующем} уголовно-процессуальном законе России

Согласно действующей ч. 3 ст. 56 УПК РФ не подлежат допросу в качестве свидетелей лица, которым какие-то сведения, не подлежащие разглашению, стали известны в связи с осуществлением профессиональной или общественной деятельности. Перечень этих лиц по мере накопления отечественного опыта реализации норм о свидетельском иммунитете дополнялся. В первоначальную редакцию УПК РФ 2001 г. в этот перечень были включены судьи и присяжные заседатели; адвокаты - об обстоятельствах, которые стали им известны в связи с оказанием любой юридической помощи; священнослужители - об обстоятельствах, ставших им известными из исповеди; член Совета Федерации, депутат Государственной Думы без их согласия - об 
обстоятельствах, которые стали им известны в связи с осуществлением ими своих полномочий. Позднее (в 2015 г.) этот перечень был дополнен указанием на должностное лицо налогового органа - об обстоятельствах, которые стали ему известны в связи с предоставленными сведениями, содержащимися в специальной декларации, и на арбитра (третейского судью) - об обстоятельствах, ставших ему известными в ходе арбитража (третейского разбирательства). В 2020 г. - также и на Уполномоченных по правам человека в Российской Федерации и в ее регионах.

Кроме того, в п. 1 ч. 4 этой же статьи указано: «Свидетель вправе: отказаться свидетельствовать против самого себя, своего супруга (своей супруги) и других близких родственников, круг которых определен п. 4 ст. 5 настоящего кодекса».

Право не свидетельствовать против себя самого получило в науке особое наименование «привилегии против самообвинения (или самоизобличения)», и оно, как правило, образует предмет самостоятельного научного исследования, отличаемый от свидетельского иммунитета [2]. Позволим себе оставить за кадром настоящего изложения привилегию против самообвинения, а также абстрагироваться на время и от другой выделяемой в отечественной литературе частности - разграничения недопустимости допроса в качестве свидетеля и права лица, уже приобретшего этот статус, либо потенциально могущего его приобрести, отказаться от дачи показаний [5, с. 144].

Запрет на допрос судей и присяжных заседателей об обстоятельствах их участия в судебном разбирательстве представляется понятным и обусловленным охраняемой самим же уголовно-процессуальным законом «тайной совещательной комнаты». Законодатель подчеркнул, что обязанность хранить эту тайну должна соблюдаться профессиональными и непрофессиональными судьями и вне судебного разбирательства по конкретному судебному делу, что она не ограничена временем и что государство берет на себя обязательство оградить эту тайну от попыток ее раскрыть во имя реализации любого интереса. Здесь законодатель не допустил никаких оговорок и исключений.
Нельзя не приветствовать практически безграничное расширение круга обстоятельств, о которых не может быть допрошен адвокат, оказывавший когда-либо какую-либо квалифицированную юридическую помощь любому лицу. Адвокатская тайна - очевидная социальная ценность, объективно связанная с конституционным правом каждого на квалифицированную юридическую помощь, а также на охрану частной жизни, личной и семейной тайны. Обращаясь к адвокату, человек должен быть уверен в возможности быть с адвокатом откровенным, не опасаться, что сказанное им адвокату может когда-нибудь навредить ему, его близким, да и вообще кому бы то ни было.

Необходимость защиты охраняемых правом частных и публичных интересов обеспечением свидетельского иммунитета судей и адвокатов представляется очевидной. Остается только гадать, почему этот вопрос не был решен российским законодателем раньше. Столь же очевидной является и необходимость предоставления свидетельского иммунитета близким родственникам обвиняемого. Однако здесь в российском законе не обошлось без явной редакционной нелепости, на которую уже обращалось внимание в прежних наших публикациях [6, с. 90]. В п. 4 ст. 5 УПК РФ к числу «близких родственников» российским законом отнесены супруг, супруга, притом, что супруги по определению близкими родственниками не являются и быть не могут по закону.

\section{Свидетельский иммунитет}

\section{в уголовно-процессуальном законе Германии}

Свидетельскому иммунитету в уголовно-процессуальном законе Федеративной Республики Германия - Strafprozessordnung der Bundes Republic Deutschland (далее также и StPOdBRD) посвящено два основных параграфа - 52 и 53 - с весьма характерными названиями, которые говорят сами за себя.

$\S 52$ StPOdBRD называется Zeugnisverweigerungsrecht der Angehörige des Beschuldigten, что буквально должно переводиться так: «Право на отказ от свидетельствования близких обвиняемого». Слово 
Angehörige является производным от глагола angehören («принадлежать», «состоять членом» какой-то малой социальной группы, не обязательно семьи). То есть речь идет о том, что в российском законе названо «близкими лицами» (п. 3 ст. 5 УПК РФ), только в тексте российского УПК этот термин к свидетельскому иммунитету отношения не имеет.

B перечне $\S 52$ StPOdBRD указаны: помолвленные (Verlobte) обвиняемого; его супруг или супруга (Ehegatte), «также если брак более не существует» (auch wenn die Ehe nicht mehr besteht), лица, состоящие с обвиняемым в отношениях родства или свойства (verwandten oder verschwägert) с указанием максимально допустимой степени того и другого (третей и второй соответственно), причем как в настоящем, так и в прошлом (ist oder war).

Даже если ограничиваться сравнительным анализом только перечня близких лиц, обладающих свидетельским иммунитетом, можно понять, насколько значимой для германского правопорядка признается проблема укрепления семейных уз и сохранения добрых отношений между близкими людьми даже после прекращения их формальной юридической связи друг с другом.

Перечень § 52 StPOdBRD пополняется в соответствии с меняющейся реальностью. Свидетельский иммунитет предоставлен в специальном п. 2а еще одному весьма непривычному для российских юристов субъектов - так называемому der Lebenspartner des Beschuldigten, то есть, буквально, «партнер по жизни». В российской переводной литератуpe, как нами уже отмечалось [6, с. 90], этот обладатель свидетельского иммунитета был назван либо «лицом, с которым заключен однополый брак» [3, с. 108], либо просто «сожителем» $[1$, c. 33]. Последний вариант, окажись он правдой, мог бы решить проблему свидетельского иммунитета «фактических супругов», актуальную для России и многих других стран. Но первый вариант, увы, скорее всего, более соответствует оригиналу.

$$
\S 53 \text { StPOdBRD называется }
$$
Zeugnisverweigerungsrecht der Berufsgeheimnisträger - буквально: «право на отказ свидетельствовать носителей профессиональной тайны» (der Beruf - «про- фессия», das Geheimnis - «тайна», der Träger существительное от tragen - «нести, носить»). В российском законе даже без выделения специальной статьи для носителей профессиональной тайны, ясно, что речь идет именно о них.

Перечень носителей профессиональной тайны § 53 StPOdBRD представляет не меньший интерес в контексте настоящего изложения. Правом отказаться от дачи свидетельских показаний по мотиву профессиональной тайны обладают не только собственно врачи (Ärzte), но отдельно еще и Zahnärzte, то есть «зубные врачи» - стоматологи, а также психотерапевты (Psychotherapeuten), причем отдельно - еще и детские и юношеские (Kinderund Jugend-) психотерапевты и даже аптекари (Apotheker). Свидетельским иммунитетом обладают помимо адвокатов (Rechtsanwälte) еще и аудиторы (Wirtschaftsprüfer), патентные поверенные (Patentanwälte), нотариусы (Notare) и т. д. Очевидным представляется то, что названные профессионалы являются носителями множества личных и семейных тайн, в том числе и охраняемой российскими федеральными законами врачебной и иной медицинской тайны, а также - тайны банковских вкладов, коммерческой тайны и т. д. Именно поэтому причины, препятствующие закрепление свидетельского иммунитета за представителями перечисленных профессий в российском законе, являются загадкой.

\section{Вероятные причины различий в нормативно-правовом определении свидетельского иммунитета}

Такие уголовно-процессуальные институты, как свидетельский иммунитет, формируются под воздействием множества факторов, система которых индивидуальна для разных государств. Германский законодатель, как видим, отказался от привычной для российского уголовного процесса формулировки «не могут быть допрошены в качестве свидетелей» в пользу «права на отказ свидетельствовать». И касается это по закону и близких обвиняемого, и носителей профессиональной тайны. Полагаем, что в российской формулировке есть важный оградительный потенциал: лиц, обладающих свидетельским иммунитетом в силу их обязанности хранить чужие 
тайны, бессмысленно склонять к даче показаний, шантажировать неприятностями в случае отказа дать показания, взывать к совести и каким-то иным образом домогаться их показаний. Их просто нельзя даже вызвать на допрос.

Обширность и разнообразие перечня «носителей профессиональной тайны» в германском законе объясняется, как полагаем, существенно бо́льшим опытом Германии в развитии рыночных отношений и сопутствующем ему развитии правовой системы.

Согласно п. 4 ч. 3 ст. 56 УПК РФ не подлежит допросу в качестве свидетеля «священнослужитель - об обстоятельствах, ставших ему известными из исповеди». Приведем аналогичную формулировку первого пункта $§ 53$ StPOdBRD: Geistliche über das, was ihnen in ihrer Eigenschaft als Seelsorger anvertraut worden oder bekanntworden ist. Буквально это переводится так: «Священники о том, что им в их качестве духовного наставника (die Seele “душа", der Sorger - "заботящийся, хлопочущий” - от глагола sorgen - “заботиться, хлопотать". - A. T.), было доверено или стало известно». Германия - так же, как и Россия многоконфессиональная страна. Полагаем, что германский вариант вполне заслуживает заимствования и российским законодателем, просто потому, что он более точен: любое общение верующего со священником, называть ли его исповедью в самом широком понимании этого слова или нет, должно быть защищено от разглашения полученных при этом сведений.

Сравнительно-правовой анализ свидетельского иммунитета как одного из частных вопросов уголовного процесса позволяет лишний раз убедиться в том, сколько резервов для совершенствования национальных правовых систем в целом открывает сравнительное правоведение, позволяя оптимизировать не только многие конкретные законодательные формулировки, но и общие ориентиры развития национальных правовых систем.

\section{СПИСОК ЛИТЕРАТУРЫ}

1. Бутов, В. Н. Процессуальное положение свидетеля по УПК ФРГ (в новой редакции) / В. Н. Бугов
// Вестник Оренбургского государственного университета. - 2009. - № 3. - С. 33-35.

2. Вилкова, Т. Ю. Привилегия против самоизобличения (nemo tenetur se ibsem accusare) в системе принципов уголовного судопроизводства / Т. Ю. Вилкова // Законы России: опыт, анализ, практика. -2016. - № 4. - С. 15-20.

3. Головенков, П. Уголовно-процессуальный кодекс Федеративной Республики Германия Strafprozessordnung (StPO) : Научно-практический комментарий и перевод текста закона ; со вступительной статьей профессора Уве Хелльманна «Введение в уголовный процессуальное право ФРГ» / П. Головенков, Н. Спица. - Потсдам, 2012.

4. Карнеева, Л. М. Следственный иммунитет и его значение / Л. М. Карнеева // Основания и порядок реализации уголовной ответственности. Куйбышев, 1989. - С. 111-115.

5. Научно-практический комментарий к Уголовно-процессуальному кодексу Российской Федерации / под общ. ред. В. М. Лебедева. - М., 2014. $-851 \mathrm{c}$.

6. Тарасов, А. А. Уголовно-процессуальная компаративистика и проблема точности перевода юридических терминов / А. А. Тарасов // Законы России: опыт, анализ, практика. - 2016. - № 12. C. 87-91.

\section{REFERENCES}

1. Butov V.N. Protsessualnoe polozhenie svidetelya po UPK FRG (v novoj redakcii) [Procedural Position of a Witness Under the Code of Criminal Procedure of the Federal Republic of Germany (new edition)]. Vestnik Orenburgskogo gosudarstvennogo universiteta [Bulletin of the Orenburg State University], 2009, no. 3, pp. 33-35.

2. Vilkova T.Yu. Privilegiya protiv samoizoblicheniya (nemo tenetur se ibsem accusare) v sisteme printsipov ugolovnogo sudoproizvodstva [Privilege Against Self-Incrimination (nemo tenetur se ibsem accusare) in the System of Criminal ${ }^{\mathrm{j} u s t i c e}$ Principles]. Zakony Rossii: opyt, analiz, praktika [Laws of Russia: Experience, Analysis, Practice], 2016, no. 4, pp. 15-20.

3. Golovenkov P., Spitsa N. Ugolovnoprotsessualnyj kodeks Federativnoj Respubliki Germaniya - Strafprozessordnung (StPO): Nauchnoprakticheskij kommentarij i perevod teksta zakona so vstupitelnoj statyoj professora Uve Hellmanna «Vvedenie v ugolovnyj protsessualnoe pravo FRG» [The Criminal Procedure Code of the Federal Republic of Germany - Strafprozessordnung (StPO). Scientific and Practical Commentary and Translation of the Text of the Law with an Introductory Article by Professor Uwe Hellmann "Introduction to Criminal 
Procedure Law of the Federal Republic of Germany"]. Potsdam, 2012.

4. Karneeva L.M. Sledstvennyj immunitet i ego znachenie [Investigative Immunity and its Significance]. Osnovaniya i poryadok realizatsyi ugolovnoj otvetstvennosti. Kuibyshev, 1989, pp. 111-115.

5. Lebedev V.M., ed. Nauchno-prakticheskij kommentarij k Ugolovno-processualnomu kodeksu Rossijskoj Federatsii [Scientific and Practical
Commentary on the Criminal Procedure Code of the Russian Federation]. Moscow, 2014. 851 p.

6. Tarasov A.A. Ugolovno-protsessualnaya komparativistika i problema tochnosti perevoda yuridicheskikh terminov [Criminal Procedural Comparative studies and the Problem of the Accuracy of Translation of Legal Terms]. Zakony Rossii: opyt, analiz, praktika [Laws of Russia: experience, analysis, practice], 2016, no. 12, pp. 87-91.

\section{Information About the Author}

Alexander A. Tarasov, Doctor of Sciences (Jurisprudence), Professor, Head of the Department of Criminal Law and Procedure, Bashkir State University, Zaki Validi St, 32, 450076 Ufa, Russian Federation, aatar@mail.ru, rector@bsunet.ru,https://orcid.org/0000-0001-6743-5517

\section{Информация об авторе}

Александр Алексеевич Тарасов, доктор юридических наук, профессор, заведующий кафедрой уголовного права и процесса, Башкирский государственный университет, ул. Заки Валиди, 32, 450076 г. Уфа, Российская Федерация, aatar@mail.ru, rector@bsunet.ru, https://orcid.org/0000-0001-6743-5517 